\title{
Wet and Dry Deposition Flux of Major Inorganic Ions at A High- Altitude Site in Himalayan Region (India)
}

\author{
ANSHU SHARMA ${ }^{1}$ \\ ${ }^{1}$ School of Environmental Sciences \\ Jawaharlal Nehru University \\ New Delhi India. anshuu.jnu@gmail.com
}

\begin{abstract}
Atmospheric deposition leads to accumulation of various pollutants which affects surface waters and terrestrial environments. Once the pollutants released into the atmosphere, its fate is decided by several processes such as transformation, transport, and deposition rate depending upon the species characteristics. Removal of these pollutants mainly occur through wet and dry deposition processes. Despite the significant impact of atmospheric pollutants, their deposition through these processes are not extensively reported in the Himalayan region of India. Hence, the present study was carried out to understand the scavenging of major inorganic ions through snow and dust, with special emphasis on the estimation of wet deposition fluxes in the Himalayan region. Wet and dry deposition of water soluble inorganic species were measured concurrently from January 2016 to February 2017 at Nirmand Village in Kullu District (Himachal Pradesh). Snow samples were collected on event basis while the dustfall samples were collected on ten days basis. In order to investigate the chemical composition of snow and dustfall, samples were analysed for $\mathrm{pH}$, conductivity, and concentrations of water-soluble ions. The results showed that the $\mathrm{pH}$ of the snowmelt samples ranged from 5.30 to 7.09 with an average of 6.38 indicating alkaline nature of snowmelt samples. The concentration of ions in snow samples followed the order- $\mathrm{Cl}->\mathrm{NH} 4+>\mathrm{Ca} 2+=\mathrm{K}+>$ $\mathrm{Na}+=\mathrm{SO} 42->\mathrm{NO} 3->\mathrm{Mg} 2+=\mathrm{F}-$. In dustfall, $\mathrm{Ca} 2+$ was the major cation and SO42- was the major anion. Source fraction calculations revealed that anthropogenic, crustal and marine sources contributed $40 \%, 33 \%$ and $72 \%$ ionic components in snowmelt, respectively. The study site has significant influence of non-marine sources. Both local emissions as well as long range transport (LRT) of pollutants were found to be the sources of these ionic species over the Himalayan region. Wet deposition was dominated by $\mathrm{Cl}-$, $\mathrm{SO} 42-$, NO3-, NH4+ and $\mathrm{Ca} 2+$ ions. Results suggested that $\mathrm{Cl}-, \mathrm{NH} 4+$ and NO3were primarily scavenged through wet deposition process, while $\mathrm{Ca} 2+$ and SO42- were scavenged primarily through dustfall.
\end{abstract}

